\title{
Can Carbon Offset Policies Be Effectively Implemented in All Regions of China? An Evolutionary Game Analysis of Decision-Making Dynamics of Local Governments
}

\author{
Qiao Peng ${ }^{1}\left(\mathbb{D}\right.$, Wanting $\mathrm{Xu}^{2,3}$ and Yao Xiao ${ }^{2,3, *}$ \\ 1 School of Statistics, Tianjin University of Finance and Economics, Tianjin 300222, China; \\ pengqiao@tjufe.edu.cn \\ 2 Center for Innovation and Development Studies, Beijing Normal University, Zhuhai 519085, China; \\ 202031410004@mail.bnu.edu.cn \\ 3 School of Economics and Resource Management, Beijing Normal University, Beijing 100875, China \\ * Correspondence: xiaoyao@188.com
}

Citation: Peng, Q.; Xu, W.; Xiao, Y. Can Carbon Offset Policies Be Effectively Implemented in All Regions of China? An Evolutionary Game Analysis of Decision-Making Dynamics of Local Governments. Sustainability 2022, 14, 1591. https:// doi.org/10.3390/su14031591

Academic Editor: Baojie He

Received: 27 December 2021

Accepted: 26 January 2022

Published: 29 January 2022

Publisher's Note: MDPI stays neutral with regard to jurisdictional claims in published maps and institutional affiliations.

Copyright: () 2022 by the authors Licensee MDPI, Basel, Switzerland. This article is an open access article distributed under the terms and conditions of the Creative Commons Attribution (CC BY) license (https:// creativecommons.org/licenses/by/ $4.0 /)$.

\begin{abstract}
Carbon offset policies are an effective means of coordinating regional ecological conservation, promoting environmentally friendly economic development, and achieving carbon neutrality; they are being gradually implemented in all regions of China. This study analyzed the decisionmaking behavior of local governments before and after the introduction of incentive and restraint mechanisms. To this end, it constructed a dynamic evolutionary game model for local governments with a carbon surplus and those with a carbon deficit. The results indicate that it is difficult to implement carbon offset policies between regions without the intervention of the central government. They also show that the effects of different incentive and restraint mechanisms vary significantly. Specifically, a mechanism that targets both carbon surplus and carbon deficit local governments and a unilateral mechanism that targets only carbon deficit local governments are shown to be effective. Finally, the results indicate that the implementation costs of incentive and restraint mechanisms differ, and their implementation intensity affects the time required for carbon offset policies to be rolled out in all regions. Based on these findings, we propose policy recommendations for promoting the implementation of carbon offset policies in all regions of China and alleviating carbon emission pressure.
\end{abstract}

Keywords: carbon offset; local government; evolutionary game theory; incentives and restraints

\section{Introduction}

With the deepening of global environmental protection and sustainable development, as well as the carbon neutrality targets proposed by many countries worldwide, low-carbon green development has become an international development trend [1]. In September 2020, at the United Nations General Assembly, Chinese President Xi Jinping announced that China would aim to attain $\mathrm{CO}_{2}$ emissions peak before 2030 and achieve carbon neutrality before 2060. However, there are disparities in the economic development levels, resource endowments, energy consumption structures, industrial structures, and ecological pressures of China's regions [2]. This results in significant differences in their carbon emissions and carbon sequestration capacity, which seriously threaten sustainable economic and social development [3]. Carbon offsetting is an effective means of coordinating regional environmental protection, promoting economic development, and achieving carbon neutrality; it has begun to be gradually implemented in various regions of China [4]. The implementation of carbon offset policies will directly affect whether China can achieve carbon emission targets and high-quality economic development.

Carbon offsetting essentially regards national carbon emission space as a scarce resource [5] and carbon sequestration capacity as a means of gain. By comparing the carbon 
emission reduction level of each region with its determined carbon emission threshold, regions can be divided into carbon deficit and carbon surplus regions [6]. Regions with carbon deficit compensate carbon surplus regions through financial payments or market instruments to achieve the equitable and coordinated economic and ecological development of each region [6,7]. China's regions with carbon deficit are generally economically developed regions with low carbon sequestration capacity and high carbon emission levels. They often over-occupy the carbon emission space of the whole country in pursuit of rapid economic development, resulting in the destruction of the overall ecological environment of the country and the creation of negative externalities [8]. China's carbon surplus regions are often economically underdeveloped regions with better carbon sequestration capacity and lower occupation of carbon emission space. If carbon surplus regions more actively reduce their carbon emissions, then carbon deficit regions can enjoy free spillover positive ecological externalities. However, carbon surplus regions would pay the cost of protecting carbon sinks or giving up development opportunities $[9,10]$. It is the game dilemma of carbon surplus and carbon deficit regions regarding carbon emission reduction and ecological conservation compensation that makes interregional ecological conservation deviate from the optimal state.

How can carbon offset policies be effectively implemented by local governments in China to achieve carbon emission reduction and high-quality economic development? This paper will study this issue and creatively adopt an evolutionary game method to describe and analyze the interest driving and interaction mechanism between local governments in the implementation process of carbon compensation policy, explores the reasons why carbon offset policies cannot be effectively implemented by local governments in China, and further introduces three incentive and restraint mechanisms into the evolutionary game model to analyze whether the three mechanisms can improve the implementation effect of carbon offset policies, so as to provide policy advice to realize the coordinated development of carbon emission reduction and regional economy.

\section{Literature Review}

Ecological compensation has recently become a hotspot. The existing research on ecological compensation mainly used the analysis methods of game theory and empirical research. The research of adopting game-theoretic methods focused on the interaction mechanism among ecological compensation participants, while the research of adopting the empirical methods focused on estimating the impact of different ecological compensation variables on carbon emissions.

(1) Recent studies that have used game theory to analyze stakeholders involved in carbon offsetting have mainly focused on the following three aspects: carbon offsetting for natural resources, carbon offsetting for tourism, and carbon pollution transferring. Research on carbon offsetting of natural resources has mainly focused on carbon offsetting of resources such as watersheds, forestry, and minerals. Carbon offsetting in watersheds is the most mature area of research due to the clear relationship between the benefits and losses of upstream and downstream stakeholders. By constructing an evolutionary game model of rewards and penalties of upstream and downstream governments, scholars have determined the costs of rewards and penalties between different regions [11-14]. They have also studied the relationship between the cost of watershed environmental protection and the intensity of implementing carbon offsetting and additional watershed environmental protection benefits and the volume of carbon offsetting $[11,15,16]$. Forestry carbon offsetting can be conducted either between the government, forestry enterprises, and forestry consumers [17] or between the government of a protected area and that of a beneficiary area $[18,19]$. By constructing a game model, it has been found that the government's compensation method of "producer support" is likely to be ineffective in the long run. However, the compensation method of "consumer support" effectively combines institutional supply and market mechanisms, which is more likely to create equilibrium in the long run. Additionally, it is easy to fall into the "prisoner's dilemma" of forest 
ecological management without central government incentive and restraint mechanisms. The optimal stable equilibrium strategy can be achieved by limiting the penalties and rewards issued by the central government [20-22]. The relevant stakeholders of carbon offsetting of mineral resources include the central government, local governments, central enterprises, local enterprises, and rural residents [23,24]; two or three of them can be selected to construct a game model. Studies have shown that, under government supervision, increasing subsidies to carbon offsetting enterprises can motivate them to conduct carbon offsetting work [25-27]. Research on tourism carbon offsetting mainly includes matrix games that revolve around the government, residents, and tourism enterprises to analyze game behavior [28-30]. They effectively explored conditions for the formation of a stable game equilibrium between two sides and proposed relevant suggestions for carbon offsetting. In addition, some scholars use game theory to study carbon pollution in different countries or regions. Nkuiya et al. used dynamic game method to study the impact of carbon emission decisions in different countries on national welfare and found that the threat of a possible jump in damages or catastrophe may induce a lower or larger emission level and initial welfare due to multiple equilibria [31]. Dockner et al. studied commodity trade and pollution emission of two countries by using dynamic game method with incomplete information and analyzed the impact of different institutional arrangements on the overall welfare of the two countries [32]. Other studies focus on international trade, carbon emission transferring, and carbon emission allocation [33,34].

(2) Scholars using empirical research methods mainly estimate the impact of carbon offset variables on carbon emissions. Haya et al. studied the influence of California's second-generation compliance compensation plan on carbon emissions and found that carbon offsets may reduce total emissions by reducing compliance costs and increase the uncertainty of whether the emission target was achieved [35]. Some scholars proposed a life cycle emission accounting method to evaluate the impact of different carbon offset projects on carbon emissions [36,37]. Calel et al. estimated the waste caused by subsidies in the implementation of a carbon offset policy in India [38]. McAfee found that in the best case, carbon offsets would not lead to a change in total emissions by estimating the emissions of the US fossil fuel industry [39]. Some other scholars have studied the impact of carbon emissions and net savings rate on economic growth [40,41].

In summary, we find that the existing studies of regional carbon offsetting using game-theoretic methods mainly focused on watershed, forestry, and mineral carbon offsetting, as well as tourism carbon offsetting. Few scholars have systematically studied carbon offsetting between carbon surplus and carbon deficit regions from the perspective of decision-making dynamics of local governments. Therefore, this study constructed an evolutionary game model to analyze whether carbon offsetting policies could be implemented effectively by local governments in China and help the Central Government of China to construct incentive and restraint mechanisms to promote effective implementation of carbon offsetting policies.

\section{Evolutionary Game Analysis of Carbon Offset Policies}

\subsection{Methodology}

Evolutionary game is a recent development of game theory. Originating in the field of biology, it was first proposed by Maynard Smith et al. [42] when studying symmetric population games; they claim the basic concept of evolutionary game is the evolutionarily stable strategy (ESS). It abandons the assumption of complete rationality in classical game theory, takes finite rationality as the premise, combines game theory analysis with dynamic evolution process analysis, and puts the interaction between individuals into the background of evolution. Evolutionary game theory differs from classical game theory in that it focuses on the dynamic adjustment process of the strategies by individuals with bounded rationality in uncertain environments. It assumes that the participant is not a hyper-rational individual with infinite reasoning ability, and unlike classical game, it does not see the participant as capable of achieving the Nash equilibrium strategy through calculation and 
making choices accordingly. Rather, it is through the process of incessantly repeating the game that the participant learns from the results, adjusts their strategies, and gradually narrows their choices to a stable Nash equilibrium strategy [43]. Game participants with bounded rationality adopt the replicator dynamic equation to adjust their strategies, and the dynamic equation can be expressed as below [44].

$$
F\left(x_{v}\right)=\frac{d x_{v}}{d t}=x_{v}\left[E\left(x_{v}\right)-\bar{E}\right]
$$

$x_{v}$ is the probability of a strategy being adopted by the game participant, $E\left(x_{v}\right)$ is the expected benefit of adopting the $v$ strategy, and $\bar{E}$ is the average benefit the participant gains when adopting all possible strategies.

\subsection{Game Model Construction for Carbon Offset Policies}

The stakeholders of interregional carbon offsetting include the central government, local governments at all levels, local residents, enterprises, and social organizations [45]. They all use available resources to maximize their own interests in the process of carbon offsetting. To facilitate analysis, this study selected the central and local governments, which have the greatest direct interests, as the game subjects. Local governments are further divided into carbon deficit and carbon surplus local governments.

(1) Central government: In the carbon offsetting game, the central government's role is that of an organizer, coordinator, and arbitrator, whose aim is to guarantee the fair, coordinated, and sustainable development of the economy and environment in each region [46].

(2) Carbon surplus local governments: To reduce carbon emissions in their regions, protect the ecological environment, and promote sustainable development, local governments with carbon surpluses may choose to invest in energy-saving and emission reduction or carbon storage projects. To promote local economic development, they may also select to utilize existing resources fully to develop their economy without investing in ecological environmental conservation. Therefore, local governments with carbon surpluses can choose between "conservation" and "no conservation" strategies to maximize the benefits to their region's economy and environment. Carbon surplus local governments that adopt the conservation strategy will pay cost $C$, which represents the sum of the direct costs of reducing carbon emissions and protecting the ecological environment, as well as the cost of lost economic development opportunities. Additionally, carbon surplus local governments who adopt a conservation strategy obtain benefits $B$ from improving the local ecological environment through energy conservation, reduced emissions, and carbon storage projects. They may receive carbon offsetting compensation $\mathrm{R}$ from carbon deficit local governments.

(3) Carbon deficit local governments: These governments may compensate carbon surplus governments for contributing to the carbon emission reduction of the whole country and sequestering a large volume of carbon generated by their local economic development, which reduces the impact on the environment. However, they may also consider it their right to enjoy the ecological environment and choose not to compensate them. As such, local governments with carbon deficits have two strategic options: compensation and no compensation. Choosing the compensation strategy entails paying compensation costs $R$. Further, the benefits to carbon deficit local governments are related to the strategies of carbon surplus local governments. When carbon surplus local governments adopt the "conservation" strategy, energy conservation, emission reduction, and carbon storage conservation projects of carbon surplus local governments that improve the overall ecological environment allow carbon deficit regions to obtain benefits $V$.

The variables involved in the upstream and downstream government behavior models and their meanings are shown in Table 1 below. 
Table 1. Variable definitions.

\begin{tabular}{|c|c|c|}
\hline Player & Parameter & Description \\
\hline Carbon Surplus Local Government & $B$ & $\begin{array}{l}\text { Carbon surplus local governments } \\
\text { adopt "protection" strategies to gain } \\
\text { revenue }\end{array}$ \\
\hline Carbon Surplus Local Government & C & $\begin{array}{c}\text { Carbon surplus local governments } \\
\text { adopt "protection" strategies to pay } \\
\text { the cost }\end{array}$ \\
\hline $\begin{array}{c}\text { Carbon Surplus Local Government } \\
\text { and Carbon Deficit Local } \\
\text { Government }\end{array}$ & $V$ & $\begin{array}{l}\text { Carbon surplus local governments } \\
\text { adopt "conservation" strategies to } \\
\text { benefit carbon deficit areas }\end{array}$ \\
\hline $\begin{array}{c}\text { Carbon Surplus Local Government } \\
\text { and Carbon Deficit Local } \\
\text { Government }\end{array}$ & $R$ & $\begin{array}{l}\text { Carbon deficit local governments pay } \\
\text { carbon compensation costs to carbon } \\
\text { surplus local governments }\end{array}$ \\
\hline Carbon Surplus Local Government & $x$ & $\begin{array}{l}\text { The proportion of carbon surplus } \\
\text { local governments adopting } \\
\text { "protection" strategy }\end{array}$ \\
\hline Carbon Deficit Local Government & $y$ & $\begin{array}{c}\text { The proportion of carbon deficit local } \\
\text { governments adopting "protection" } \\
\text { strategy }\end{array}$ \\
\hline
\end{tabular}

According to the above hypothesis, the benefit matrix of the game between carbon surplus local governments and carbon deficit governments can be obtained, as shown in Table 2. The benefits of carbon surplus local governments and carbon deficit local governments adopting no conservation and no compensation strategies are $(0,0)$. This strategy combination is used as the reference standard for the benefits of other strategy combinations. Of the four strategy choices, the socially optimal strategy is for carbon surplus local governments to choose conservation and for carbon deficit local governments to choose compensation. The role of the central government is to guide local governments to select the socially optimal strategy through macro-control.

Table 2. Local government carbon offset game benefit matrix.

\begin{tabular}{cccc}
\hline \multirow{2}{*}{$\begin{array}{c}\text { Carbon Surplus Local } \\
\text { Government }\end{array}$} & Conservation & $B+R-C, V-R$ & Carbon Deficit Local Government \\
\cline { 2 - 4 } & No conservation & $R,-R$ & No Compensation \\
\hline \multirow{2}{*}{$\begin{array}{c}\text { Compensation } \\
\text { Coy }\end{array}$} & & 0,0 \\
\hline
\end{tabular}

\subsection{Game Model Analysis of Carbon Offset Policy}

It is assumed that the proportion of carbon surplus local governments that adopt a conservation strategy is $x(0 \leq x \leq 1)$, and that of those that adopt a no conservation strategy is $1-x$. However, the proportion of carbon deficit local governments that adopt a compensation strategy is $y(0 \leq y \leq 1)$ and that of those that adopt a no compensation strategy is $1-y$.

(1) Evolutionary game analysis of carbon surplus local governments: It is assumed that the expected benefits of adopting conservation and no conservation strategies by carbon surplus local governments and the average expected benefits of all carbon surplus local governments are $U_{s 1}, U_{s 2}$, and $U_{s}$, respectively, where

$$
\begin{gathered}
U_{s 1}=y(B+R-C)+(1-y)(B-C)=B-C+y R \\
U_{s 2}=y R \\
U_{s}=x U_{s 1}+(1-x) U_{s 2}
\end{gathered}
$$


According to evolutionary game theory assumptions, carbon surplus local governments adjust their strategies according to the replicator dynamics equation:

$$
\frac{d x}{d t}=x\left(U_{s 1}-U_{s}\right)=x(1-x)\left(U_{s 1}-U_{s 2}\right)=x(1-x)(B-C)
$$

Let $\frac{d x}{d t}=0$, when the carbon surplus local government stops adjusting its strategy to reach equilibrium, then $x_{1}^{*}=0, x_{2}^{*}=1$.

The replicator dynamics equation shows that when $B>C, x_{2}^{*}=1$ is the evolutionarily stable equilibrium point of carbon surplus local governments. When the ecological benefits gained by carbon surplus local governments from adopting the conservation strategy are greater than the sum of their investment in carbon emission reduction and ecological environmental conservation and the costs of lost economic development opportunities, carbon surplus local governments will adopt the conservation strategy. When $B<\mathrm{C}$, $x_{1}^{*}=0$ is the evolutionarily stable equilibrium point of carbon surplus local governments, and all carbon surplus local governments will adopt the no conservation strategy. When $B=C$, there is no difference between carbon surplus local governments adopting the conservation strategy or the no conservation strategy.

(2) Evolutionary game analysis of carbon deficit local governments: It is assumed that the expected benefits of adopting compensation and no compensation strategies by carbon deficit local governments and the average expected benefits of all carbon deficit local governments are $U_{d 1}, U_{d 2}$, and $U_{d}$, respectively, where

$$
\begin{gathered}
U_{d 1}=x(V-R)+(1-x)(-R)=x V-R \\
U_{s 2}=x V \\
U_{d}=y U_{d 1}+(1-y) U_{d 2}
\end{gathered}
$$

According to evolutionary game theory assumptions, carbon deficit local governments adjust their strategies according to the replicator dynamics equation:

$$
\frac{d y}{d t}=y\left(U_{d 1}-U_{d}\right)=y(1-y)\left(U_{d 1}-U_{d 2}\right)=y(1-y)(-R)
$$

Let $\frac{d y}{d t}=0$, when the carbon deficit local government stops adjusting its strategy to reach equilibrium, then $y_{1}^{*}=0, y_{2}^{*}=1$.

The replicator dynamics equation shows that all carbon deficit local governments will adopt a no compensation strategy, as $R>0, y_{1}^{*}=0$ is the evolutionarily stable equilibrium point for carbon deficit local governments.

Consequently, there are four equilibrium points in the game between carbon surplus and carbon deficit local governments: $(0,0),(0,1),(1,0)$, and $(1,1)$. However, only $(0,0)$ and $(1,0)$ may be stable equilibrium points-without central government intervention, no carbon deficit local governments will choose to compensate carbon surplus local governments. Local governments cannot rely on themselves to implement the central government's carbon offset policy. Central government incentive and restraint mechanisms are required to ensure the implementation of the carbon offset policy.

\subsection{Game Analysis of Carbon Offset with the Introduction of Incentive and Restraint Mechanisms}

According to the evolutionary game analysis of carbon surplus and carbon deficit local governments provided above, without the intervention of the central government, no compensation is the evolutionarily stable strategy of carbon deficit local governments, and the socially optimal goal (conservation and compensation) cannot be achieved. The central government must establish incentive and restraint mechanisms to guide local government strategies to converge to the socially optimal goal. The central government can construct the following three types of incentives and restraints to guide local government behavior toward the socially optimal goal. 
1. The incentive and restraint mechanism for carbon surplus local governments: When a carbon surplus local government conducts ecological conservation, the central government gives a reward $P$; otherwise, a penalty $Q$ is given. This study terms this Incentive and Restraint Mechanism 1.

2. The incentive and restraint mechanism for carbon deficit surplus local governments: When carbon deficit local governments compensate carbon surplus local governments, the central government gives a reward $P$; otherwise, a penalty $Q$ is given. This study terms this as Incentive and Restraint Mechanism 2.

3. The incentive and restraint mechanism for carbon surplus and carbon deficit local governments: This is when carbon surplus local governments conduct ecological conservation, carbon deficit local governments compensate them, the central government gives both sides a reward $P$ but imposes a penalty $\mathrm{F}$ if one of the two governments does not fulfill its corresponding obligations, and the size of penalty given to both sides is $Q$. This study terms this Incentive and Restraint Mechanism 3.

\subsubsection{Game Analysis of Carbon Offsetting under Incentive and Restraint Mechanism 1}

Constructing the local government carbon offsetting game model according to Incentive and Restraint Mechanism 1, the benefit matrix of the carbon surplus and carbon deficit local governments game can be obtained, as shown in Table 3, where

$$
\begin{gathered}
U_{s 1}=y(B+R-C+P)+(1-y)(B-C+P)=B+P-C+y R \\
U_{s 2}=y(R-Q)+(1-y)(-Q)=y R-Q
\end{gathered}
$$

Table 3. Benefit matrix of the local government carbon offset game under Incentive and Restraint Mechanism 1.

\begin{tabular}{cccc}
\hline \multirow{2}{*}{} & \multicolumn{2}{c}{ Carbon Deficit Local Government } \\
\cline { 2 - 4 } & Compensation & No Compensation \\
\hline \multirow{2}{*}{$\begin{array}{c}\text { Carbon Surplus Local } \\
\text { Government }\end{array}$} & Conservation & $B+R-C+P, V-R$ & $B-C+P, V$ \\
\cline { 2 - 4 } & No conservation & $R-Q,-R$ & $-Q, 0$ \\
\hline
\end{tabular}

The replicator dynamics of a strategy adjustment by carbon surplus local governments are

$$
\frac{d x}{d t}=x(1-x)\left(U_{s 1}-U_{s 2}\right)=x(1-x)(B+P+Q-C)
$$

When $\frac{d x}{d t}=0$, that is, carbon surplus local governments stop strategy adjustment to reach equilibrium, then $x_{1}^{*}=0, x_{2}^{*}=1$. When $B+P+Q>C, x_{2}^{*}=1$ is the evolutionarily stable strategy of carbon surplus local governments; otherwise, $x_{1}^{*}=0$ is the evolutionarily stable strategy of carbon surplus local governments.

Similarly, the replicator dynamics of a strategy adjustment by carbon deficit local governments remains the same: $\frac{d y}{d t}=y\left(U_{d 1}-U_{d}\right)=y(1-y)\left(U_{d 1}-U_{d 2}\right)=y(1-y)(-R)$. Subsequently, $y_{1}^{*}=0$ is the evolutionarily stable equilibrium point of carbon deficit local governments.

Therefore, according to the above analysis, the incentive and restraint mechanism for carbon surplus local governments only affects their equilibrium strategy. Adjusting the reward and penalties can encourage them to promote carbon emission reduction or strengthen carbon storage projects. Furthermore, the rewards and penalties can replace each other to achieve the same results. However, they cannot change the behavior of carbon deficit local governments, and the "no compensation" strategy is still the evolutionarily stable strategy of carbon deficit local governments. Therefore, the incentive and restraint mechanism that only targets carbon surplus local governments does not work effectively. 
3.4.2. Game Analysis of Carbon Offsetting under Incentive and Restraint Mechanism 2

Constructing the local government carbon offsetting game model according to Incentive and Restraint Mechanism 2, the benefit matrix of the carbon surplus and carbon deficit local governments game can be obtained, as shown in Table 4 . The replicator dynamics of the carbon surplus local governments strategy adjustment remains the same:

$$
\frac{d x}{d t}=x\left(U_{s 1}-U_{s}\right)=x(1-x)\left(U_{s 1}-U_{s 2}\right)=x(1-x)(B-C)
$$

Table 4. Benefit matrix of the local government carbon offset game under Incentive and Restraint Mechanism 2.

\begin{tabular}{cccc}
\hline \multirow{2}{*}{} & & \multicolumn{2}{c}{ Carbon Deficit Local Government } \\
\cline { 2 - 4 } & Compensation & No Compensation \\
\hline \multirow{2}{*}{$\begin{array}{c}\text { Carbon Surplus Local } \\
\text { Government }\end{array}$} & No conservation & $R,-R+C, V-R+P$ & $B-C, V-Q$ \\
\cline { 2 - 4 } & Conservation & $0,-Q$ \\
\hline
\end{tabular}

When $\frac{d x}{d t}=0$, that is, the carbon surplus local government stops strategy adjustment to reach equilibrium, then $x_{1}^{*}=0, x_{2}^{*}=1$, When $B>C, x_{2}^{*}=1$ is the evolutionarily stable equilibrium point of carbon surplus local governments.

The expected benefits of adopting compensation and no compensation for carbon deficit local governments are

$$
\begin{gathered}
U_{d 1}=x(V-R+P)+(1-x)(-R+P)=x V-R+P \\
U_{s 2}=x V-Q
\end{gathered}
$$

The replicator dynamics of strategy adjustment then becomes

$$
\frac{d y}{d t}=y(1-y)(P+Q-R) .
$$

Let $\frac{d y}{d t}=0$, that is, the carbon deficit local government stops strategy adjustment to reach equilibrium, then $y_{1}^{*}=0, y_{2}^{*}=1$.

When $P+Q>R, y_{2}^{*}=1$ is the stable equilibrium strategy-when the sum of rewards and penalties from the central government to carbon deficit local governments is greater than the compensation paid to carbon surplus local governments, carbon deficit local government choose the compensation strategy as the evolutionarily stable strategy. Otherwise, the no compensation strategy is the evolutionarily stable strategy for carbon deficit local governments.

According to the above analysis, the restraint and incentive mechanism for carbon deficit local governments only affects their equilibrium strategy. When the conservation benefit to carbon surplus local governments is greater than the cost, the restraint and incentive mechanism for carbon deficit local governments can have better role results. Adjusting the rewards and penalties can encourage carbon deficit local governments to compensate carbon surplus local governments and help carbon surplus local governments choose the conservation strategy.

\subsubsection{Game Analysis of Carbon Offsetting under Incentive and Restraint Mechanism 3}

Constructing the local government carbon offsetting game model according to Incentive and Restraint Mechanism 3, the benefit matrix of the game between the carbon surplus and the carbon deficit local governments can be obtained, as shown in Table 5. 
Table 5. Benefit matrix of the local government carbon offset game under Incentive and Restraint Mechanism 3.

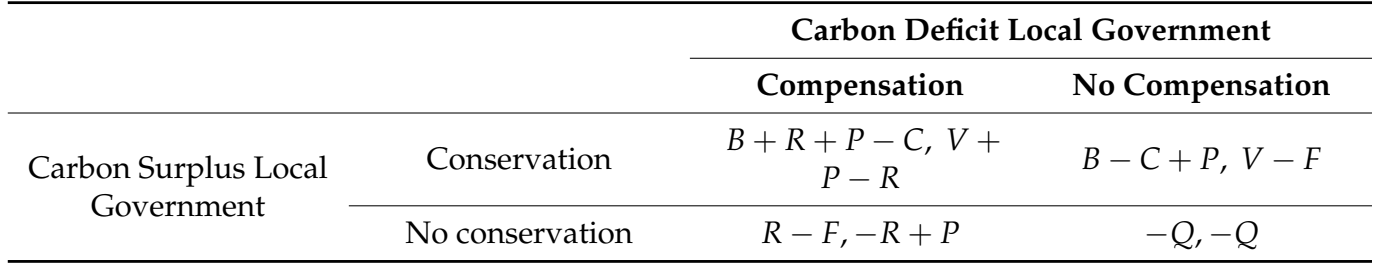

The replicator dynamics equations for strategy adjustments by carbon surplus local governments and carbon deficit local governments, respectively, are

$$
\begin{gathered}
\frac{d x}{d t}=x(1-x)[y(F-Q)+P+Q+B-C] \\
\frac{d y}{d t}=y(1-y)[x(F-Q)+P+Q-R] .
\end{gathered}
$$

Let $\frac{d x}{d t}=0, \frac{d y}{d t}=0$ can give $x_{1}^{*}=0 . x_{2}^{*}=1, y_{3}^{*}=b=\frac{P+Q+B-C}{F-Q}, y_{1}^{*}=0, y_{2}^{*}=1$, $x_{3}^{*}=a=\frac{P+Q-R}{F-Q}$. If $0 \leq a \leq 1,0 \leq b \leq 1$, then there are five equilibria in the evolutionary game between carbon surplus and carbon deficit local governments: $(0,0),(0,1),(1,0)$, $(1,1),(a, b)$.

Let $F(x)=\frac{d x}{d t}$ and $G(y)=\frac{d y}{d t}$. We use the Jacobian matrix to analyze the stability of each local equilibrium point of this two-dimensional dynamical system:

$$
J=\left[\begin{array}{ll}
\frac{\partial F(x)}{\partial x} & \frac{\partial F(x)}{\partial y} \\
\frac{\partial G(y)}{\partial x} & \frac{\partial G(y)}{\partial y}
\end{array}\right]=\left[\begin{array}{ll}
c_{11} & c_{12} \\
c_{21} & c_{22}
\end{array}\right]
$$

The stable equilibrium point of the replicator dynamics equation satisfies the following two conditions.

(1) $\operatorname{tr}(J)=c_{11}+c_{22}<0$.

(2) $\operatorname{det}(J)=c_{11} c_{22}-c_{12} c_{21}>0$.

Table 6 was obtained from the Jacobian matrix of the replicator dynamics equation.

Table 6. Jacobian matrix of equilibrium points.

\begin{tabular}{ccccc}
\hline Equilibrium Point & $c_{11}$ & $c_{12}$ & $c_{21}$ & $c_{22}$ \\
\hline$(0,0)$ & $P+Q+B-C$ & 0 & 0 & $P+Q-R$ \\
\hline$(0,1)$ & $F+P+B-C$ & 0 & 0 & $-(P+Q-R)$ \\
\hline$(1,0)$ & $-(P+Q+B-C)$ & 0 & 0 & $P+F-R$ \\
\hline$(1,1)$ & $-(F+P+B-C)$ & 0 & 0 & $-(P+F-R)$ \\
\hline$\left(x_{3}^{*}, y_{3}^{*}\right)$ & 0 & $c_{12}^{*}$ & $c_{21}^{*}$ & 0 \\
\hline & & & &
\end{tabular}

The stability of the equilibrium points can be judged from the Jacobian matrix as follows.

(1) When $F+P+B-C>0, P+F-R>0, P+Q+B-C>0$, and $P+Q-R>0$, $(1,1)$ is the only stable equilibrium point. The phase diagram of the dynamic evolution of carbon surplus and carbon deficit local governments is shown in Figure 1a. That is, the central government's incentives and penalties for carbon surplus and carbon deficit local governments' behavioral strategies are sufficiently strong to compensate for the net costs of compensation and conservation in any case, and local governments' behavior will converge to the social optimum, ensuring that the central government's carbon offset policy can be 
effectively implemented. However, larger rewards and penalties require not only greater financial support from the central government, but also more administration costs in the process of implementing the rewards and penalties.

C

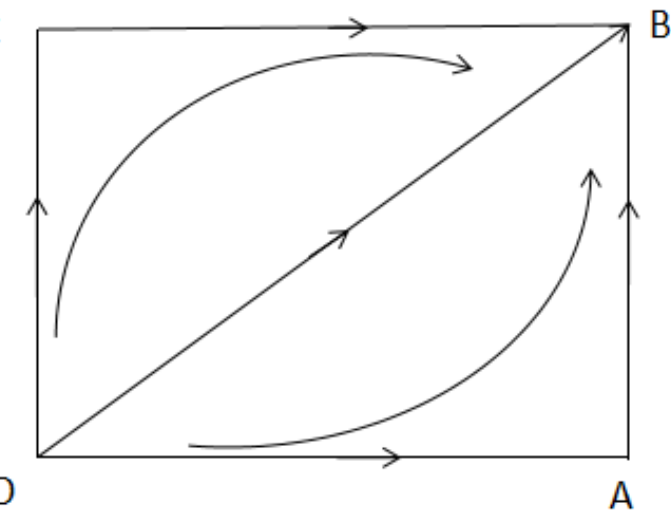

(a)

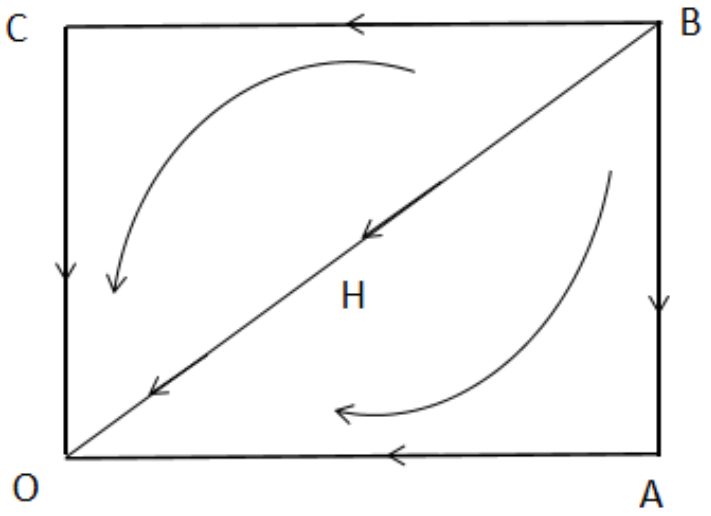

(c)

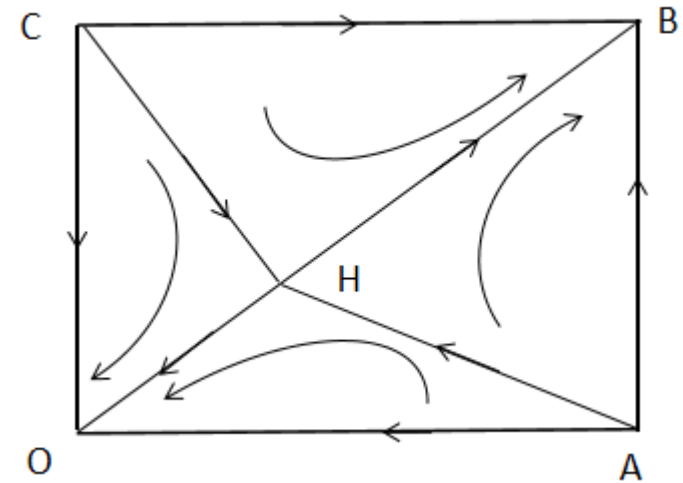

(b)

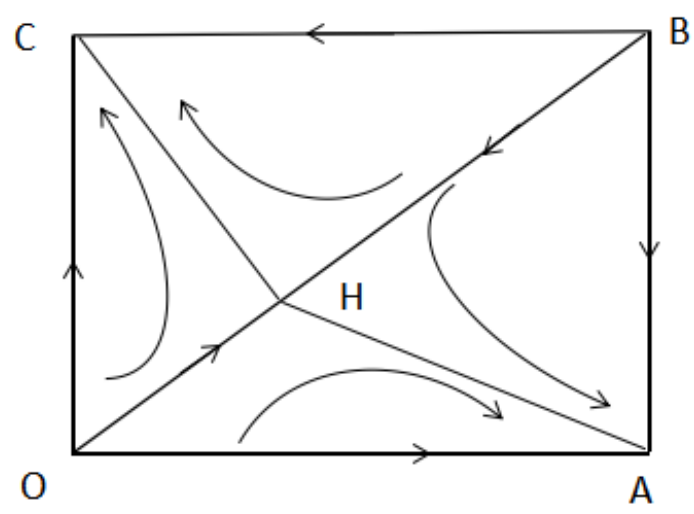

(d)

Figure 1. Phase diagrams of the evolutionary game of local governments. (a) $F+P+B-C>0$, $P+F-R>0, P+Q+B-C>0$, and $P+Q-R>0$; (b) $F+P+B-C>0, P+F-R>0$, $P+Q+B-C<0$, and $P+Q-R<0$; (c) $F+P+B-C<0, P+F-R<0, P+Q+B-C<0$, and $P+Q-R<0$; (d) $F+P+B-C<0, P+Q-R>0, P+Q+B-C>0$, and $P+Q-R<0$.

(2) When $F+P+B-C>0, P+F-R>0, P+Q+B-C<0$, and $P+Q-R<0$, both $(0,0)$ and $(1,1)$ are stable equilibrium points, and $\left(x_{3}^{*}, y_{3}^{*}\right)$ are saddle points. The phase diagram of the dynamic evolution of carbon surplus and carbon deficit local governments are shown in Figure $1 \mathrm{~b}$. That is, there is no guarantee that the $(1,1)$ state will definitely be realized, and according to the phase diagram of the dynamic evolution of carbon surplus local governments and carbon deficit local governments (Figure 1b), it is known that the probability of convergence to the equilibrium state $(1,1)$ is $P_{B}=S_{A B C H}$, whereby the larger the area of $\mathrm{ABCH}$, the higher the probability of convergence to the $(1,1)$ state, and the more effectively the carbon offset policy can be implemented. The area of $\mathrm{ABCH}$ is related to the saddle point $\mathrm{H}$. When point $\mathrm{H}$ converges to $(0,0)$, its area is larger, and the coordinates of point $\mathrm{H}$ are $\left(\frac{R-(P+Q)}{Q-F}, \frac{C-(P+Q+B)}{Q-F}\right)$; therefore, when $P+Q$ is larger, point $\mathrm{H}$ will converge to the origin $(0,0)$. This indicates that the greater the rewards and penalties from the central government, the higher the probability that the local government game will converge to $(1,1)$, and the more effectively carbon offset policies can be implemented. 
(3) When $F+P+B-C<0, P+F-R<0, P+Q+B-C<0$, and $P+Q-R<0$, $(0,0)$ is the only stable equilibrium point. The phase diagram of the dynamic evolution of carbon surplus and carbon deficit local governments is shown in Figure 1c.

(4) When $F+P+B-C<0, P+Q-R>0, P+Q+B-C>0$, and $P+Q-R<0$, $(0,1)$ and $(1,0)$ are stable equilibrium points, and $\left(x_{3}^{*}, y_{3}^{*}\right)$ are saddle points. The phase diagram of the dynamic evolution of carbon surplus and carbon deficit local governments is shown in Figure 1d.

The above discussion states that under Incentive and Restraint Mechanism 3, the central government's rewards and penalties for both carbon surplus and carbon deficit local governments have a greater impact on both parties' decisions. Only when certain conditions are met can local governments' decisions be driven closer to the socially optimal goal.

\section{Discussion}

The goal of the central government is to converge the behavioral decisions of carbon surplus and carbon deficit local governments toward the equilibrium point $(1,1)$ - the conservation and compensation state-by means of incentive and restraint mechanisms that adjust the reward and penalty parameters $P, Q$, and $F$. According to the stable equilibrium point of the evolutionary game between local governments, it is known that different incentive and restraint mechanisms have different effects. The size of the parameters of the same mechanism determines the speed of convergence of local governments to the target equilibrium state. This section further discusses the effect of different mechanisms and the effect of the size of the reward and penalty parameter values on the speed of convergence based on the above game analysis.

\subsection{Effectiveness of Different Incentives and Restraints Mechanisms}

To guide the local government game to converge toward the social optimum and enable local governments to implement carbon offset policies, this study considers the construction of three types of incentive and restraint mechanisms, which are designed and implemented by the central government: an incentive and restraint mechanism for carbon surplus local governments, an incentive and restraint mechanism for carbon deficit local governments, and an incentive and restraint mechanism for both carbon surplus and carbon deficit local governments. Analysis of the equilibrium state of the evolutionary game between local governments shows the following.

(1) The incentive and restraint mechanism for carbon surplus local governments only affects the equilibrium strategy of the carbon surplus local governments. When $P+Q>C-B$, the sum of incentives and penalties of the central government's strategy for carbon surplus local governments is greater than the net cost of conservation, which can promote a reduction in carbon emissions or stronger carbon storage projects among carbon surplus local governments, and incentive and penalty policies are interchangeable and will achieve the same results. However, it does not change the behavior of carbon deficit local governments, and the no compensation strategy is still an evolutionarily stable strategy for them. Therefore, an incentive and restraint mechanism only for carbon surplus local governments does not effectively promote the implementation of carbon offset policies among all local governments.

(2) The incentive and restraint mechanism for carbon deficit local governments only affect the equilibrium strategy of the carbon deficit local governments. When the benefits of conservation for carbon surplus local governments are greater than the costs, incentives and restraints are more effective, and carbon surplus local governments will spontaneously choose the conservation strategy. Therefore, as long as $P+Q>R$, the sum of incentives and penalties from the central government to carbon deficit local governments is greater than the compensation to carbon surplus local governments, and carbon deficit local governments will select the compensation strategy as an evolutionarily stable strategy, thereby achieving the socially desirable outcome. Therefore, the central government can 
promote the implementation of carbon offset policies at a lower cost when the benefits of conservation for carbon surplus local governments outweigh the costs.

(3) Incentives and restraints for both carbon surplus local governments and carbon deficit local governments have a large impact on the equilibrium state of the local government game. By adjusting the parameters, the behavioral strategies of local governments can be made to converge to any state. To ensure that the carbon offset policy can be implemented and let the state of local governments converge to the conservation and compensation state, the incentive and restraint mechanism of the central government must satisfy the following condition: $F+P+B-C>0, P+F-R>0$. That is, the sum of the central government's rewards for carbon surplus local governments adopting a conservation strategy and the penalties for adopting a no conservation strategy must not only be greater than the net cost of conservation, but the sum of rewards for carbon deficit local governments adopting a compensation strategy, and the penalties for adopting a no compensation strategy should be greater than the compensation for carbon surplus local governments.

\subsection{Effect of Different Incentive and Restraint Parameters on the Speed of Convergence of the Evolutionary Game}

The central government's rewards and penalties for local governments can induce the local government game to converge to the conservation and compensation strategy and affect the speed of convergence to that equilibrium. Below the examples of Incentive and Restraint Mechanism 2 and Incentive and Restraint Mechanism 3 are employed to illustrate the effect of different reward and penalty parameters on the speed of convergence of the evolutionary game.

(1) The effect of parameters on the speed of convergence of the evolutionary game under Incentive and Restraint Mechanism 2:

According to the evolutionary game analysis of local governments under Incentive and Restrain Mechanism 2 in Section 3, it is known that when $B>C, P+Q>R,(1,1)$ is the stable equilibrium point of the evolutionary game of carbon surplus local governments and carbon deficit local governments. The replicator dynamics equations for strategic adjustments of carbon surplus local governments and carbon deficit local governments are assigned according to the conditions $\frac{d x}{d t}=x(1-x)(B-C)$ and $\frac{d y}{d t}=y(1-y)(P+Q-R)$, and they were simulated numerically using MATLAB.

First, we considered the simulation of the local government evolutionary game in the absence of central government intervention. Let $B=0.6, C=0.1, R=0.6$, and let the initial $x_{0}=0.2, y_{0}=0.2$. The numerical simulation of the local government evolutionary game using MATLAB yielded Figure 2, which shows that carbon deficit local governments will not consciously implement carbon offset policies in the absence of central government intervention.

When the central government's Incentive and Restraint Mechanism 2 is introduced, and it satisfies the condition $P+Q>R$, let $P+Q=1.2,1.4,1.6,1.8$ obtain the digital simulation diagrams Figure 3, respectively. The figures show that as the central government's rewards to carbon deficit local governments increase, carbon deficit local governments converge to the "compensation" strategy more quickly, while the time taken for carbon surplus local governments to converge to the conservation strategy remains unchanged. This means that the incentive and restraint mechanism targeted at carbon deficit local governments has no effect on the behavioral decisions of carbon surplus local governments. 


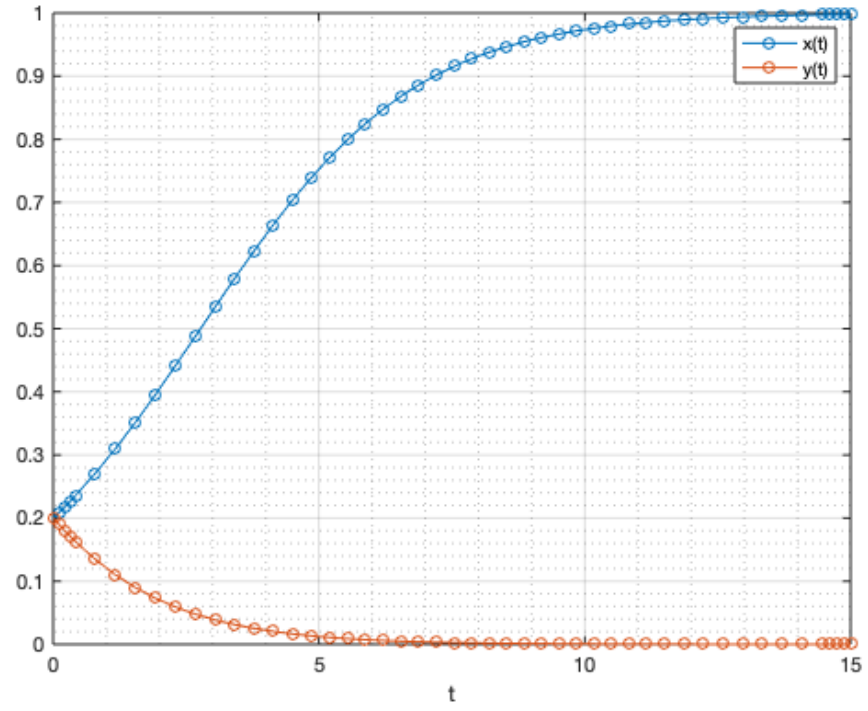

Figure 2. Simulation of the evolutionary game between local governments under incentive and restraint mechanisms.

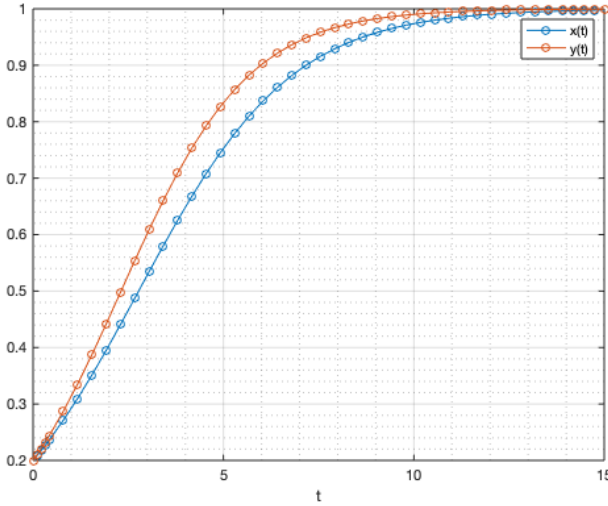

(a)

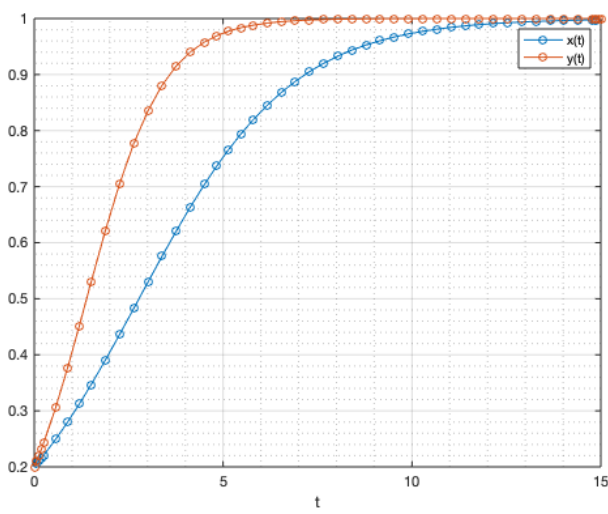

(c)

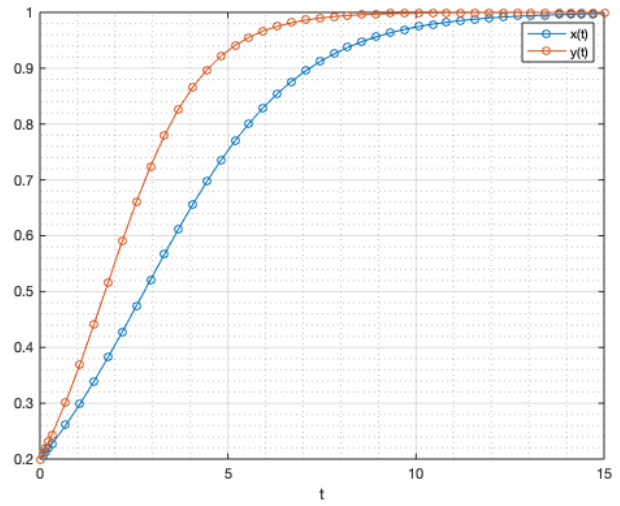

(b)

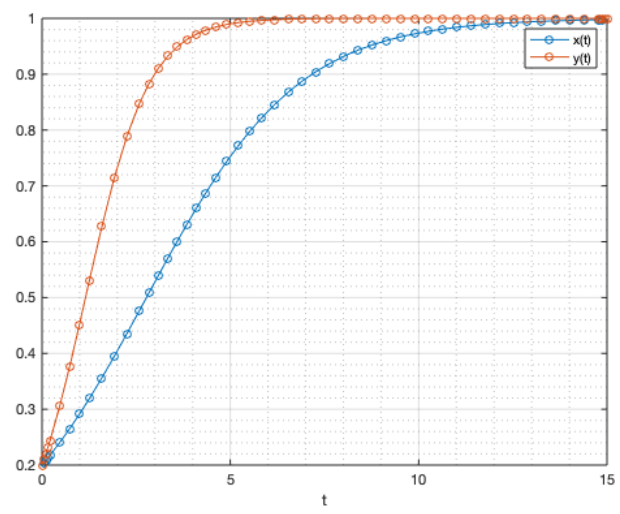

(d)

Figure 3. Simulation of the evolutionary game between local governments under Incentive and Restraint Mechanism 2. (a) $P+Q=1.2$; (b) $P+Q=1.4$; (c) $P+Q=1.6$; (d) $P+Q=1.8$.

(2) The effect of parameters on the speed of convergence of the evolutionary game under Incentive and Restraint Mechanism 3:

According to the evolutionary game analysis of local governments under Incentive and Restraint Mechanism 3 in Section 3, it is clear that $(1,1)$ is the only stable equilibrium 
point when $F+P+B-C>0, P+F-R>0, P+Q+B-C>0$, and $P+Q-R>0$. The replicator dynamics equations for strategic adjustments by carbon surplus and carbon deficit local governments are assigned according to this condition:

$$
\begin{gathered}
\frac{d x}{d t}=x(1-x)[y(F-Q)+P+Q+B-C] \\
\frac{d y}{d t}=y(1-y)[x(F-Q)+P+Q-R]
\end{gathered}
$$

Let $x_{0}=0.2, y_{0}=0.2, B=0.6, C=0.1, R=0.6, F-Q=0.5$, and let $P+Q=1.2,1.4,1.6,1.8$ obtain the numerical simulations of Figure $4 \mathrm{a}-\mathrm{d}$, respectively. The figures show that as the central government increases rewards and penalties for carbon surplus local governments and carbon deficit local governments, carbon surplus and carbon deficit local governments converge to the conservation and compensation strategy at a faster rate.

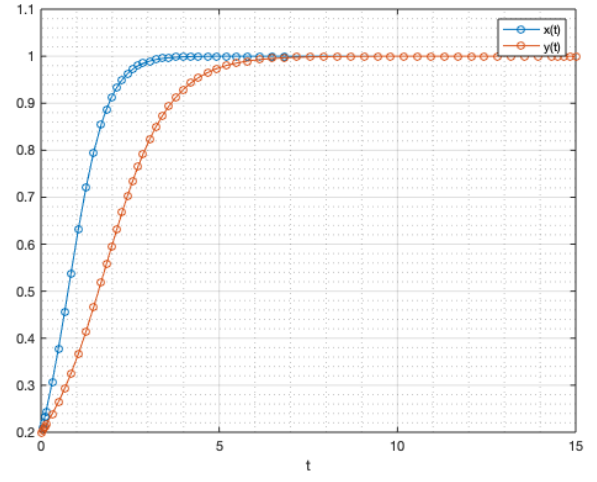

(a)

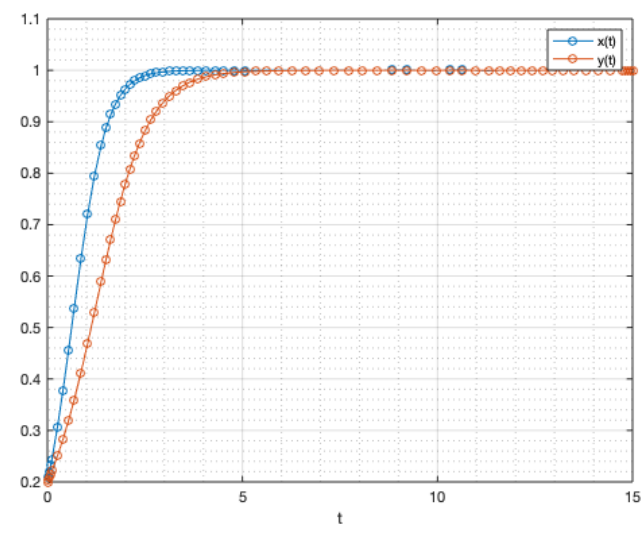

(c)

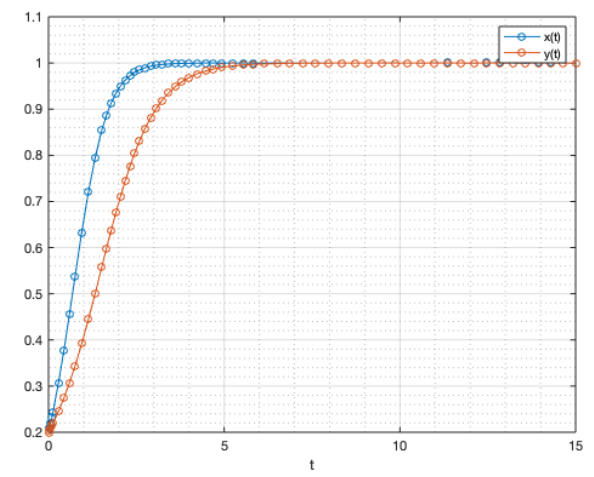

(b)

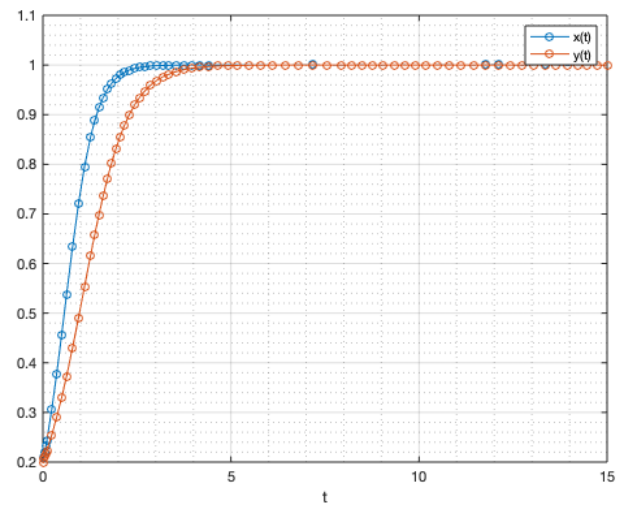

(d)

Figure 4. Simulation of the evolutionary game between local governments under Incentive and Restraint Mechanism 3. (a) $P+Q=1.2$; (b) $P+Q=1.4$; (b); (c) $P+Q=1.6$; (d) $P+Q=1.8$.

In summary, an incentive and restraint mechanism for both carbon surplus and carbon deficit local governments is the most effective way to promote the socially optimal behavior of local governments and ensure the effective implementation of carbon offset policies. Moreover, the time required to ensure the effective implementation of carbon offset policies in all regions is shorter as the incentives and penalties imposed by the central government become stronger. Although stronger rewards and penalties imposed by the central government and a wider range of targets ensures more effective implementation of carbon offset policies, these conditions create a greater financial burden and higher 
implementation costs. Therefore, in the implementation of carbon offset policies, there is still a trade-off between the effectiveness and cost of policy implementation. The existing studies on carbon compensation policies believe that it is difficult to ensure the effective implementation of carbon compensation policies by the initiative of local governments themselves, and it is necessary to rely on a unified big government organization or the coordination and management of the central government to motivate local governments to implement the compensation policies [47-49]. However, they did not study the effects of different incentives, and the costs of implementing them in detail.

\section{Conclusions and Policy Implications}

\subsection{Implications for Research}

With low carbon development becoming an international development trend, China is facing increased pressure to reduce carbon emissions due to its massive economic volume and need for further development. Carbon emissions and sequestration vary significantly among regions, thus China is promoting transactions between carbon surplus areas and carbon deficit areas through carbon offset policies to achieve the dual aims of reducing emissions and encouraging economic development. The temptation for carbon surplus areas to benefit at the expense of carbon deficit regions can make it difficult to implement carbon offsetting policies spontaneously. In this paper, we analyzed the effect of carbon offset policies by constructing an evolutionary game model including carbon surplus and carbon deficit local governments. We found the following:

(1) In the absence of central government intervention, it is difficult to implement carbon offset policies among local governments, and it is necessary to rely on the central government to establish an incentive and restraint mechanism to make it possible for carbon offset policies to be implemented by local governments. The effects of different incentives and restraints differ greatly: The incentive and restraint mechanism that targets carbon surplus local governments has an impact only on the behavior of carbon surplus local governments, and it cannot motivate carbon deficit local governments to compensate carbon surplus local governments. The incentive and restraint mechanism that targets carbon deficit local governments has an impact only on the equilibrium strategy of carbon deficit local governments, and when the conservation benefits to carbon surplus local governments are greater than the costs, the incentive and restraint mechanism is more effective. The incentive and restraint mechanism that targets both carbon surplus and carbon deficit local governments has a greater influence on the behavior of both, and it can effectively promote the implementation of carbon emission policies.

(2) There are alternative effects of central government rewards and penalties on the behavior of local governments, and the same effect on the behavior of local governments is achieved by decreasing rewards and increasing penalties or increasing rewards and decreasing penalties. Nevertheless, different rewards and penalties have different implementation costs. Penalties can increase the central government's fiscal revenue, while rewards consume fiscal revenue. The different incentive and restraint mechanisms also have different implementation costs. The incentive and restraint mechanism that targets carbon deficit local governments is not as effective as the mechanism for both carbon surplus and carbon deficit local governments, but its implementation costs are lower. Thus, it requires less financial support from the central government. Further, as central government rewards and penalties increase, the time needed to ensure carbon offset policies are replicated in all regions is shortened.

\subsection{Policy Implications}

Based on the above findings, the following recommendations are made to promote the effective implementation of carbon offset policies in all regions of China, alleviate the pressure on carbon emissions, and achieve the dual objectives of economic development and environmental protection. 
(1) We recommend establishing a diversified carbon offsetting mechanism based on central government compensation and supplemented by local government and market compensation. Under this scenario, the central government compensates carbon surplus local governments through financial incentives and policy support of an incentive and restraint mechanism. Local governments provide compensation in the forms of financial compensation, technical support, and project cooperation according to the principle of "whoever benefits pays". Further, market-based compensation is used as a useful supplement to the compensation of the central government and local governments, mainly to establish a carbon emission trading system, with interregional carbon offsetting through regional carbon storage trading. Additionally, various private organizations, enterprises, and individuals could be encouraged to participate in carbon offsetting by purchasing carbon storage from the China Green Carbon Foundation or making donations.

(2) We recommend exploring the formulation of a scientific and reasonable carbon offsetting standards. The formulation of compensation standards should consider local economic development, the income of residents, price levels, and the costs of reducing carbon emissions and protecting the ecological environment borne by the compensation entity. It is necessary to avoid low compensation standards and carbon surplus local governments lacking enthusiasm for ecological conservation as well as to avoid a one-sizefits-all compensation standard that ignores the ability of localities or their willingness to pay compensation. It is necessary to build a two-way coordination mechanism for carbon offsetting between regions and to comprehensively coordinate the bilateral interests of the parties paying and receiving compensation, to achieve coordinated regional economic and ecological development.

\section{Limitations and Further Research}

This paper adopts evolutionary game method to describe and analyze the interest driving and interaction mechanism among local governments in the implementation process of carbon compensation policy, explores the reasons why carbon offset policies cannot be effectively implemented by local governments in China, and further introduces three incentive and restraint mechanisms into the evolutionary game model to analyze whether the three mechanisms can improve the implementation effect of carbon offset policies. However, there are still the following two shortcomings: (1) Evolutionary game methods are more used to describe the mutual influence mechanism of different stakeholders decision-making. Therefore, empirical models are needed to further verify the research conclusions of this paper. (2) The relationship between regional economic development and carbon offset is not included in the evolutionary game model of local governments. According to relevant studies [50], environmental Kuznets curve phenomenon shows the mutual impact of economic development and environmental quality, and considering the relationship between regional economic development and carbon compensation in the evolutionary game model becomes the direction of further research in the future.

Author Contributions: Q.P. and Y.X. conducted the modeling and data analysis and drafted of the manuscript. W.X., Y.X. and Q.P. conceptualized the study, designed the experiment, and contributed to the manuscript. Y.X., Q.P. and W.X. contributed to the acquisition and computation of data. All authors critically revised the manuscript for important intellectual content and approved the final version. All authors have read and agreed to the published version of the manuscript.

Funding: This work was supported by Statistical Scientific Key Research Project of China (2021LZ33) and Statistical Scientific Key Research Project of Zhejiang (21TJZZ25).

Institutional Review Board Statement: Not applicable (this study did not involve humans or animals).

Informed Consent Statement: Not applicable (this study did not involve humans).

Data Availability Statement: The data used to support the findings of this study are available from the corresponding author upon request. 
Conflicts of Interest: The authors declare no conflict of interest.

\section{References}

1. Sonter, L.J.; Simmonds, J.S.; Watson, J.E.M.; Jones, J.P.G.; Kiesecker, J.M.; Costa, H.M.; Bennun, L.; Edwards, S.; Grantham, H.S.; Griffiths, V.F.; et al. Local conditions and policy design determine whether ecological compensation can achieve No Net Loss goals. Nat. Commun. 2020, 11, 2072. [CrossRef] [PubMed]

2. Song, M.; Zhao, X.; Shang, Y. The impact of low-carbon city construction on ecological efficiency: Empirical evidence from quasi-natural experiments. Resour. Conserv. Recycl. 2020, 157, 104777. [CrossRef]

3. Sun, R.; Liu, T.; Chen, X.; Yao, L. A biomass-coal co-firing based bi-level optimal approach for carbon emission reduction in China. J. Clean. Prod. 2021, 278, 123318. [CrossRef]

4. Wang, W.; Wang, W.; Xie, P.; Zhao, D. Spatial and temporal disparities of carbon emissions and interregional carbon compensation in major function-oriented zones: A case study of Guangdong province. J. Clean. Prod. 2020, 245, 118873. [CrossRef]

5. Zhai, T.; Wang, J.; Fang, Y.; Huang, L.; Liu, J.; Zhao, C. Integrating Ecosystem Services Supply, Demand and Flow in Ecological Compensation: A Case Study of Carbon Sequestration Services. Sustainability 2021, 13, 1668. [CrossRef]

6. Yang, Y.; Yang, S. Are industrial carbon emissions allocations in developing regions equitable? A case study of the northwestern provinces in China. J. Environ. Manag. 2020, 265, 110518. [CrossRef]

7. Yan, F.; Wang, Y.; Du, Z.; Chen, Y.; Chen, Y. Quantification of ecological compensation in Beijing-Tianjin-Hebei based on carbon footprint calculated using emission factor method proposed by IPCC. Trans. Chin. Soc. Agric. Eng. 2018, 34, 15-20. [CrossRef]

8. Yu, B.; Xu, L.; Yang, Z. Ecological compensation for inundated habitats in hydropower developments based on carbon stock balance. J. Clean. Prod. 2016, 114, 334-342. [CrossRef]

9. Miao, Y.; Kong, C.; Wang, L.; Mu, J.; Lu, X.; Bao, J.; Li, H. A provincial lateral carbon emissions compensation plan in China based on carbon budget perspective. Sci. Total Environ. 2019, 692, 1086-1096. [CrossRef]

10. Yue, D.; Sarkar, A.; Cui, Y.; Qian, L.; Minjuan, Z.; Das, J.C. Ecological compensation of grain trade within urban, rural areas and provinces in China: A prospect of a carbon transfer mechanism. Environ. Dev. Sustain. 2021, 23, 16688-16712. [CrossRef]

11. Hu, D.; Liu, H.; Chen, X.; Chen, Y. Research on the ecological compensation standard of the basin pollution control project based on evolutionary game theory and by taking Xiangjiang River as a case. Front. Eng. Manag. 2019, 6, 575-583. [CrossRef]

12. Gao, X.; Shen, J.; He, W.; Sun, F.; Zhang, Z.; Guo, W.; Zhang, X.; Kong, Y. An evolutionary game analysis of governments' decision-making behaviors and factors influencing watershed ecological compensation in China. J. Environ. Manag. 2019, 251, 109592. [CrossRef] [PubMed]

13. Wei, C.; Luo, C. A differential game design of watershed pollution management under ecological compensation criterion. J. Clean Prod. 2020, 274, 122320. [CrossRef]

14. Sun, H.; Gao, G.; Li, Z. Research on the cooperative mechanism of government and enterprise for basin ecological compensation based on differential game. PLoS ONE 2021, 16, e0254411. [CrossRef] [PubMed]

15. Yi, Y.; Wei, Z.; Fu, C. A differential game of transboundary pollution control and ecological compensation in a river basin. Complexity 2020, 2020, 6750805. [CrossRef]

16. Li, F.; Pan, B.; Wu, Y.; Shan, L. Application of game model for stakeholder management in construction of ecological corridors: A case study on Yangtze River Basin in China. Habitat Int. 2017, 63, 113-121. [CrossRef]

17. Wang, Z.; Yang, T.; Liu, H.; Yuan, M.; Li, C. Evaluation and Dynamic Mechanism of Ecological Space in a Densely Urbanized Region During a Rapidly Growing Period-A Case Study of the Wu-E-Huang-Huang Metropolitan Interlocking Region. Sustainability 2019, 12, 73. [CrossRef]

18. Andrés-Domenech, P.; Martín-Herrán, G.; Zaccour, G. Cooperation for sustainable forest management: An empirical differential game approach. Ecol. Econ. 2015, 117, 118-128. [CrossRef]

19. Guo, J.Y.; Chen, S.L. Evolutionary game analysis of ecological compensation in the economic transition of state-owned forest areas. Appl. Ecol. Environ. Res. 2019, 17, 14425-14434. [CrossRef]

20. Tan, L.; Zhang, Q.; Zhang, Y. Modelling a Compensation Standard for a Regional Forest Ecosystem: A Case Study in Yanqing District, Beijing, China. Int. J. Environ. Res. Public Health 2018, 15, 565. [CrossRef]

21. Franklin, O.; Nasholm, T.; Hogberg, P.; Hogberg, M.N. Forests Trapped in Nitrogen Limitation—An Ecological Market Perspective on Ectomycorrhizal Symbiosis. New Phytologist. 2014, 203, 657-666. [CrossRef] [PubMed]

22. Zhao, J. Research on improving ecological compensation mechanism of mineral resources development. In Proceedings of the International Conference on E-Health Networking Digital Ecosystems and Technologies (EDT), Shenzhen, China, 17-18 April 2010; IEEE: Manhattan, NY, USA, 2010; pp. 567-570. [CrossRef]

23. Song, C.; Zhang, Z.; Ge, J. Evolution of Environmental Policy for China's Rare Earths: Comparing Central and Local Government Policies. Resour. Policy 2020, 68, 101786. [CrossRef]

24. Ding, S.; Wang, M.; Zhang, H. Intergenerational Externalities Influence for Exploitation Process of Rare Metal Minerals. Process. 2021, 9, 883. [CrossRef]

25. Yan, G.; Xue, F.; Li, Z. Research on Ecological Restoration Mechanism of Rare-Earth Mines Based on Evolutionary Game. Adv. Mater. Sci. Eng. 2020, 2020, 4201945. [CrossRef]

26. Yeoh, E.K.K.; Suruna. Environmental Dimension of Regional Development in China, with Special Focus on Grassland Ecological Compensation in Alxa League of Inner Mongolia. Contemp. Chin. Political Econ. Strateg. Relat. 2019, 5, 409-489. Available online: 
https: / www.proquest.com/docview/2264113913/fulltextPDF/3CA7CE5134064E2BPQ/1?accountid=13863 (accessed on 23 December 2021).

27. Xue, C.; Shao, C.; Gao, J. Ecological Compensation Strategy for SDG-Based Basin-Type National Parks: A Case Study of the Baoxing Giant Panda National Park. Int. J. Environ. Res. Public Health 2020, 17, 3908. [CrossRef] [PubMed]

28. Zhang, Y.; Li, Y. Willingness to Pay for Tourism Ecological Compensation and Its Influencing Factors-Taking the Best Spring in the World in Ji'nan as an Example. Iop Conf. Series. Earth Environ. Sci. 2020, 615, 12046. [CrossRef]

29. Koelble, T.A. Ecology, economy and empowerment: Eco-tourism and the game lodge industry in South Africa. Bus. Politics 2011, 13, 1-24. [CrossRef]

30. Gssling, S.; Broderick, J.; Upham, P.; Ceron, J.P.; Dubois, G.; Peeters, P.; Strasdas, W. Voluntary Carbon Offsetting Schemes for Aviation: Efficiency, Credibility and Sustainable Tourism. J. Sustain. Tour. 2007, 15, 223-248. [CrossRef]

31. Nkuiya, B. Transboundary pollution game with potential shift in damages. J. Environ. Econ. Manag. 2015, 72, 1-14. [CrossRef]

32. Dockner, E.J.; Van Long, N. International pollution control: Cooperative versus noncooperative strategies. J. Environ. Econ. Manag. 1993, 25, 13-29. [CrossRef]

33. Nkuiya, B.; Plantinga, A.J. Strategic pollution control under free trade. Resour. Energy Econ. 2021, 64, 101218. [CrossRef]

34. Nkuiya, B.; Marrouch, W.; Bahel, E. International Environmental Agreements under Endogenous Uncertainty. J. Public Econ. Theory 2015, 17, 752-772. [CrossRef]

35. Haya, B.; Cullenward, D.; Strong, A.L.; Grubert, E.; Heilmayr, R.; Sivas, D.A.; Wara, M. Managing uncertainty in carbon offsets: Insights from California's standardized approach. Clim. Policy 2020, 20, 1112-1126. [CrossRef]

36. Greene, S.; Façanha, C. Carbon offsets for freight transport decarbonization. Nat. Sustain. 2019, 2, 994-996. [CrossRef]

37. Köhl, M.; Ehrhart, H.-P.; Knauf, M.; Neupane, P.R. A viable indicator approach for assessing sustainable forest management in terms of carbon emissions and removals. Ecol. Indic. 2020, 111, 106057. [CrossRef]

38. Calel, R.; Colmer, J.; Dechezleprêtre, A.; Glachant, M. Do carbon offsets offset carbon? Cesifo Work. Pap. 2021, 9368, 1-46. [CrossRef]

39. McAfee, K. Shall the American Association of Geographers Endorse Carbon Offsets? Absolutely Not! Prof. Geogr. 2022, 74, 171-177. [CrossRef]

40. Batrancea, L.; Rathnaswamy, M.M.; Batrancea, I.; Nichita, A.; Rus, M.-I.; Tulai, H.; Fatacean, G.; Masca, E.S.; Morar, I.D. Adjusted Net Savings of CEE and Baltic Nations in the Context of Sustainable Economic Growth: A Panel Data Analysis. J. Risk Financ. Manag. 2020, 13, 234. [CrossRef]

41. Batrancea, I.; Rathnaswamy, M.K.; Batrancea, L.; Nichita, A.; Gaban, L.; Fatacean, G.; Tulai, H.; Bircea, I.; Rus, M.-I. A Panel Data Analysis on Sustainable Economic Growth in India, Brazil, and Romania. J. Risk Financ. Manag. 2020, 13, 170. [CrossRef]

42. Smith, J.M.; Price, G.R. The Logic of Animal Conflict. Nature 1973, 246, 15-18. [CrossRef]

43. Xiao, Y.; Peng, Q.; Xu, W.; Xiao, H. Production-Use Water Pricing and Corporate Water Use in China: An Evolutionary Game Theory Model. Math. Probl. Eng. 2021, 2021, 6622064. [CrossRef]

44. Peng, Q.; Xiao, Y. Will Third-Party Treatment Effectively Solve Issues Related to Industrial Pollution in China? Sustainability 2020, 12, 7685. [CrossRef]

45. Guang, Z.; Pan, G.; Zhang, W. Evolutionary Game Theoretic Analysis of Low Carbon Investment in Supply Chains Under Governmental Subsidies. Int. J. Environ. Res. Public Health 2018, 15, 2465. [CrossRef]

46. Qiu, Y.; Liu, Y.; Liu, Y.; Chen, Y.; Li, Y. An Interval Two-Stage Stochastic Programming Model for Flood Resources Allocation under Ecological Benefits as a Constraint Combined with Ecological Compensation Concept. Int. J. Environ. Res. Public Health 2019, 16, 1033. [CrossRef] [PubMed]

47. Galatowitsch, S.M. Carbon Offsets as Ecological Restorations. Restor. Ecol. 2009, 17, 563-570. [CrossRef]

48. Lu, J.-L.; Shon, Z.Y. Exploring airline passengers' willingness to pay for carbon offsets. Transp. Res. Part D Transp. Environ. 2012, 17, 124-128. [CrossRef]

49. Van Kooten, G.C.; Johnston, C.M.T. The economics of forest carbon offsets. Annu. Rev. Resour. Econ. 2016, 8, 227-246. [CrossRef]

50. Sharma, G.D.; Tiwari, A.K.; Erkut, B.; Mundi, H.S. Exploring the nexus between non-renewable and renewable energy consumptions and economic development: Evidence from panel estimations. Renew. Sustain. Energy Rev. 2021, 146, 111152. [CrossRef] 